\title{
Development of an industry-based laser manufacturing degree program
}

Judy Donnelly, Nicholas Massa, Karen Wosczyna Birch

Judy Donnelly, Nicholas Massa, Karen Wosczyna Birch, "Development of an industry-based laser manufacturing degree program," Proc. SPIE 9665, Tenth International Topical Meeting on Education and Training in Optics and Photonics, 96650P (3 June 2007); doi: 10.1117/12.2207318

SPIE Event: Tenth International Topical Meeting on Education and Training in Optics and Photonics, 2007, Ottawa, Ontario, Canada 


\title{
Development of an Industry Based Laser Manufacturing Degree Program
}

\author{
Judy Donnelly \\ Three Rivers Community College, 574 New London Turnpike, Norwich, CT 06360 \\ jdonnelly@trcc.ccommnet.edu (860) 885-2353 \\ Nicholas Massa \\ School of Technology, Central CT State University, 1516 Stanley St., New Britain, CT 06050 \\ massanim@ccsu.edu (860) 832-3232 \\ Karen Wosczyna Birch \\ Regional Center for Next Generation Manufacturing, clo CT Community Colleges; 61 Woodland St. \\ Hartford, CT 061058602447608
}

\begin{abstract}
In 2005, Connecticut's Regional Center for Next Generation Manufacturing (RCNGM) surveyed companies representing a cross section of the laser manufacturing industry in New England. A technician competency profile was created as a result of a detailed job skills survey and intensive personal interviews with company personnel. Three Rivers Community College subsequently developed a Laser Manufacturing Option to the Manufacturing Engineering Technology A.S. degree based on the competency profile, with new and revised courses featuring an emphasis on interdisciplinary skills and knowledge across several disciplines.
\end{abstract}

\section{Introduction}

\subsection{The problem: The need for a skilled manufacturing workforce}

Manufacturing was central to Connecticut's past and is critical to its economic future. The state that was home to Samuel Colt, Eli Whitney and the first submarine now produces jet engines, helicopters, nuclear submarines, fuels cells, space suits, fabricated metals, electronics and pharmaceuticals in its 5400 manufacturing companies. Although the popular perception of manufacturing is "dirty, dark and dangerous" with no future as jobs decline or are outsourced, high tech manufacturing, including the use of lasers for cutting, drilling, welding and sintering, is central to the state's economy.

In response to a 2005 survey by the Connecticut Business and Industry Association (CBIA), nearly half of Connecticut's manufacturing firms reported that job applicants did not have the skills necessary for open positions and another 19 percent reported having difficulty finding any applicants at all. [1] In addition to the difficulty of finding new employees, the state's employers face the problem of an aging workforce and large numbers of impending retirements. (Connecticut has the nation's seventh oldest workforce) It is not surprising that the availability of a workforce skilled in new technologies is a prime concern of the state's manufacturers.

\subsection{The Community Colleges' response: The Regional Center for Next Generation Manufacturing}

The driving force behind the creation of the Regional Center for Next Generation Manufacturing (RCNGM) was the success of the College of Technology (COT), a virtual organization of the twelve Connecticut Community Colleges. COT was created by the state legislature in 1992 when the state's five technical colleges were merged with its twelve community colleges. The COT's unique infrastructure provides seamless career pathways with multiple entry and exit points leading to credit certificates and Associate of Science, and Bachelor of Science degrees in engineering and technology. There are 2 COT pathway programs, Technological Studies and Engineering Science. The Associate of Science degree in Engineering Science seamlessly articulates to engineering programs at five universities, while the innovative curriculum of the Technological Studies pathway includes five industry-driven technology electives.

Tenth International Topical Meeting on Education and Training in Optics and Photonics, edited by Marc Nantel, Proc. of SPIE Vol. 9665, 96650P - @ 2007 SPIE, OSA, IEEE, ICO doi: $10.1117 / 12.2207318$ 
Although COT was originally charged with developing $2+2$ pathways from the community colleges to four-year university programs, the Technological Studies pathway in particular quickly became the practical choice for creating new programs to meet technical workforce needs. Unlike a full Associate degree program that can take years to be approved, elective options to the Technological Studies degree can be implemented in a matter of months, allowing Connecticut's Community Colleges to respond quickly to changing industry needs.

Beginning in 2001, COT and CBIA received two grants from the Advanced Technology Education (ATE) project of the National Science Foundation (NSF) to develop curriculum in cutting edge technologies and to provide faculty professional development, in large part through paid externships at local companies. Teachers from high schools and community colleges who completed industry externships created new work-based curriculum that was shared statewide through the COT's virtual network.

The creation of the Regional Center for Next Generation Manufacturing was, then, the next logical step to address the critical need for a workforce educated for the new manufacturing environment. The Center was funded by the National Science Foundation's ATE program in 2004, and its goals are: to develop programs in new technology areas with input from industry; to prepare faculty to implement industry-driven, next generation manufacturing coursework and laboratories; to make young people aware of opportunities in the new manufacturing workplace; and to increase collaboration between schools and manufacturers.

Around the same time (2005), the newly formed Connecticut Center for Advanced Technology (CCAT) received funding from the U.S. Air Force Office of Scientific Research/ National Aerospace Leadership Initiative to develop a Laser Applications Laboratory to conduct applied research on laser materials processing for military and commercial products. With so much research and development activity directed at laser material processing, it was natural that the RCNGM begin the process of developing a laser manufacturing curriculum for Connecticut's Community Colleges.

\section{Developing an industry-driven laser manufacturing curriculum}

The first step in developing an industry-driven curriculum was to determine the educational and skills outcomes necessary for new employees of the laser industry. Rather than request a large number of companies fill out a simple check-off list, we decided to conduct in-depth interviews with a small number of companies. This allowed follow up questions to clarify or expand upon survey items, and the company representatives were able to bring up competencies we had not considered in forming our survey.

During the Summer and Fall of 2005, a skills/needs assessment was conducted with nine laser companies using a modified DACUM ("Developing a Curriculum") approach. The selected companies represented a cross sectional sample of the laser manufacturing industry in the New England region involved in the manufacturing, use, and/or system integration of lasers (OEMs). These companies included:

$\begin{array}{ll}\text { JDSU Corporation } & \text { Bloomfield, CT } \\ \text { IPG Photonics Corporation } & \text { Oxford, MA } \\ \text { Coherent Laser } & \text { Bloomfield, CT } \\ \text { Zygo Corporation } & \text { Middlefield, CT } \\ \text { OFS Optics } & \text { Avon, CT } \\ \text { Photomachining Corporation } & \text { Pelham, NH } \\ \text { Rofin-Baasel Corporation } & \text { Boxborough, MA } \\ \text { Prima Laser } & \text { Springfield, MA } \\ \text { CT Center for Advanced Technology } & \text { East Hartford, CT }\end{array}$

Representatives from each company, including engineers, technicians and managers, responded to a DACUM survey, personal interviews, telephone interviews, or a combination of these, in which they were asked to provide detailed information describing job functions, tasks and duties deemed critical for a laser technician at their particular company. Anecdotal data was also compiled with regard to ancillary tasks and duties required of laser manufacturing technicians at each company in an effort to provide depth and breadth to the survey data. Sample job descriptions from companies that were hiring at the time were also collected. Survey data, interview data, and job descriptions were examined for common core competencies as well as industry-specific knowledge and skill requirements. The results were then integrated into a draft Laser Manufacturing Technician Competency Profile, in 
which critical job duties and tasks are tabulated; and a draft Laser Manufacturing Technician Competency Outline, in which detailed and measurable performance indicators (sub-tasks) for each job task were compiled. The draft Laser Manufacturing Technician Competency Profile and Outline were subsequently redistributed to each participating company for validation in which a 5-point Likert scale was used to rate the importance of each task and subtask $(1=$ not important; $5=$ very important $)$.

In addition to survey and interview data compiled, competencies obtained from the National Skills Standard in Laser Machining (NSF-ATE: Machinetool Advanced Skills Technical Education Resources (MASTER) Project, 1997) as well as the National Photonics Skill Standard for Technicians (CORD Communications, 2003) were used to triangulate the survey data. Both the MASTER Laser Machining Skill Standard and the CORD National Photonics Skills Standard detail the skills and knowledge required of the laser technician resulting from comprehensive DACUMs conducted on a national level with over 100 companies. [2,3]

The Laser Manufacturing Technician Competency Profile and Outline formed the foundation for the Regional Center for Next Generation Manufacturing (RCNGM) Laser Manufacturing Technician A.S. Degree curriculum. (Table 1) A course crosswalk template was also developed which provides a cross-reference linking the tasks and subtasks identified in the competency profile to the core technical courses in which those skills are to be developed as well as the exit-level proficiency for each measurable task and subtask (i.e., concept introduced, reinforced, or mastered). [4]

Table 1. RCNGM proposed Laser Manufacturing A.S. Degree Curriculum. Course IDs, where indicated, are common to all twelve Community Colleges.



\section{Implementation at Three Rivers Community College}

Three Rivers Community College in Norwich, Connecticut offers associate degrees in twelve technology and engineering technology areas, and one- or two-semester certificate programs in many of the same technologies. The college has the state's only two-year photonics program, the Associate in Science (A.S.) degree in Laser and Fiber 
Optic Technology (LFOT). Since 1999, graduates of the LFOT program have been working at companies that manufacture lasers, such as Coherent, IPG Photonics, Zygo and Trumpf. The program emphasis is on electronics and optics, important to laser manufacturers, but the program does not address the needs of laser users and integrators. The laser manufacturing curriculum proposed by the RCNGM provided a unique opportunity for the college to create an interdisciplinary program involving optics, lasers, electronics, material processing and manufacturing that could be exported to the other Community Colleges through the COT.

\subsection{Interdisciplinary curriculum team to the rescue}

The Three Rivers Technology Department began in the 1960s as a State Technical College, and for the most part, the autonomous technology programs worked together only when forced to by the college administration. In 2005, in response to low enrollments and a need to improve efficiency as the college plans to move to a new campus, the Director of Engineering Technology announced a reorganization of the department into "clusters" of several programs with similar courses and student outcomes. The manufacturing-related cluster, or the "Gang of Four" as it came to be called, included Laser and Fiber Optic Technology, and the TAC/ABET accredited Electrical, Mechanical and Manufacturing Engineering Technologies. The first project undertaken by the group was the creation of a laser manufacturing program.

\subsection{Ideal world meets reality}

The four program coordinators of the manufacturing-related cluster met weekly throughout the spring of 2006 to implement the RCNGM laser manufacturing program. A totally new associate degree program was out of the question; approval by the appropriate college committees, the Board of Trustees for the Community-Technical Colleges, and the State Department of Higher Education would take up to two years (or more) to obtain. There were other constraints as well, some imposed locally by the college and some by the state governing boards:

- No associate degree program may have more than 68 total credits

- One third of credits must be in general education areas- math, science, humanities, social science

- A fine arts course must be included, as well as two or more English communications courses

- No new full-time faculty could be hired

- Any new lab facilities or equipment would need to be grant funded or donated by industry.

The program coordinators decided to create a fifteen-credit elective option to the existing Manufacturing Engineering Technology program, while, at the same time, updating other courses in the program to reflect the current manufacturing workplace. This decision was not without its own constraints: only fifteen credits of an associate degree program may be changed without the approval of the Board of Trustees. The group used a combination of reformulated and/or renamed "old" courses (which needs only the approval of the college's Curriculum Committee) and a small selection of new courses to accomplish their goal. In some cases, changes will be made over two years, to keep to the fifteen-credit limit. The long-range plan is to use the basic degree structure to support additional options, for example, a Mechatronics option to build on the automated controls courses.

Table 2 shows the Manufacturing Engineering Technology degree program and the Laser Manufacturing Option, which was approved by the Board of Trustees in the summer of 2006. It should be noted that students entering the program are required to have passed College Algebra and Physics I (Mechanics) before entering the program. Students may do this through the Tech Prep program at their high school, or as additional courses taken at Three Rivers.

Much compromise was required on the part of each of the four technology programs, including eliminating some cherished traditional courses, cutting back on the number of credits for some courses, and combining similar courses previously taught in separate departments (in some cases, by assigning two faculty to "team teach" a course.) The revised degree and option reflect the enthusiastic agreement of all program coordinators involved to update and streamline courses and to create shared interdisciplinary courses wherever possible. Among the course revisions were:

- Introduction to Photonics. This was a 5 contact-hour course (3 hour class/2 hour lab) in the Laser and Fiber Optic Technology program. To fit in the new Laser Manufacturing Option, one hour was removed creating a 2 hour lecture/2 hour lab course. The new format allows the course to be taught in two 2- hour blocks, 
using a modified "studio physics" format. Each class block consists of a short (10-15 minute) introduction, followed by an inquiry based hands-on activity. The last ten minutes of class are used to report out to the group and present conclusions. This format has proven to be much more efficient than the traditional lecture/laboratory, and the same amount of material is covered in less time with no loss of student comprehension.

- Circuits and Systems. Previously, the introductory electric circuits sequence was a traditional DC circuits course (first semester) followed by AC circuits (second semester). The revised courses are a one-semester introduction to both DC and AC circuits, followed by a second semester of more rigorous circuit analysis. This approach has several benefits: the course now may be used as the course for non-majors in programs like Mechanical Engineering Technology, increasing class size; first semester students, often weak in math, have a semester to strengthen math skills before studying more complex electrical systems; and the revised course is a better fit to the high school electronics courses for which the college grants Tech Prep credit.

- Laser Safety, a one day seminar course, was expanded to a one-credit Laser and Lab Safety course, required of all Manufacturing and LFOT students.

Table 2. The Three Rivers Community College Implementation of the Laser Manufacturing A.S. Degree Program. The current Manufacturing Option (right hand side) is slated to become a Mechatronics Option.

Manufacturing Engineering Technology Core Program

Course ID General Education



\section{$\underline{\text { Title }}$}

Fine Arts Elective

Science Elective

Social Sciences Elective

Composition

Technical Writing

Principles of Statistics

Precalculus

\section{$\underline{\text { Credits }}$}

4

3

3

3

3

4

Technical Core Courses

TCN K105

BMG K218

CAD K106

CAD K107

EET K105

EET K106

EET K264/265

MEC K114

MEC K152

MEC K153

MFG K102

MFG K103

MFG K118/119
Laser and Lab Safety

Operations Management

Computer-Aided Drafting/Lab

Computer-Aided Drafting Lab

Electric Circuits \& Systems

Electric Circuits \& Systems Lab

Automated Controls I and Lab

Introduction to Structural Mechanics

Fundamentals of Eng. Graphics

Fundamentals of Eng. Graphics Lab

Manufacturing Processes

Manufacturing Processes Lab

Computer Controlled Laser Material

Processing/Lab
Manufacturing Option Courses

EET K266/267

MEC K250/252

MEC K262/263

MFG K214/215

Option Total:

Degree Total:
Automated Controls II /Lab 4

Strength of Materials/Lab 4

Materials Science/Lab 4

Tool Design/Lab
Laser Manufacturing Option Courses

PHO K101 Introduction to Photonics 3

PHO K140 Optoelectronics/Lab 4

PHO K230 Laser Electronics 4

PHO K240 Introduction to Lasers 4

15 Option Total:

67 Degree Total 


\subsection{New Courses}

Of course, it is impossible to create a meaningful new program option without adding new courses. In response to the RCNGM industry survey, an optoelectronics course was created as a parallel course to the standard Electronics I taken by Electrical Engineering technology students, but emphasizing applications in optoelectronics. At the same time, the content of the Laser Electronics course was changed to include more high power and RF electronics. These courses will be part of the LFOT program as well as the new Laser Manufacturing Option

\subsection{Computer Controlled Laser Material Processing}

The capstone course created for the program is Computer Controlled Laser Material Processing. The course covers the mechanics, components, characteristics and control of lasers used in the processing of engineering materials. Students study specific processes such as athermal processing, surface hardening, cladding, joining, cutting, marking and welding and are exposed to computer numerical control (CNC) concepts and programming. The course is taken by both Manufacturing and LFOT students, leading to an interesting mix of abilities; some students are well-versed in laser technology while others have in-depth knowledge of manufacturing processes.

To support the laboratory, the RCNGM purchased a large format 45 Watt CO2 engraver for use in the Three Rivers Manufacturing Laboratory. Students use the laser to study the effects of changing laser parameters when processing (raster engraving or vector cutting) a variety of materials. In one such experiment, students were instructed to design a procedure to methodically investigate the raster settings of speed and power for 3 types of material. Additional tests were performed at fixed speed and power settings with variations in resolution from 75 to $1200 \mathrm{dpi}$, and in a third investigation, the effects of changing lens focal length and engraving with both focused and defocused lens were also studied. Students examined the materials processed by the laser by creating photomicrographs using microscopes equipped with digital cameras and image analysis software.

The investigations required students to devise a graphic to be engraved that would allow them to effectively study the parameters being changed. The test pattern was applied repeatedly with different settings of power, speed and resolution for each material and for several focal length lenses, with results organized in a matrix format. Because of the relatively low power, the laser is restricted to various types of wood and plastic, but students were still able to draw conclusions about the "best" settings for different materials. For example, they noted that high powers used with acrylic resulted in fine drops of molten plastic being sprayed onto the surface. One group reported, " An earlier attempt to engrave wood at $100 \%$ power and $10 \%$ speed made it clear that some combinations would result in fire, the byproducts of which would be fouled lenses and destroyed samples."

Figure 1. Student study of laser engraver speed and power on wood sample, photographed at 60X.

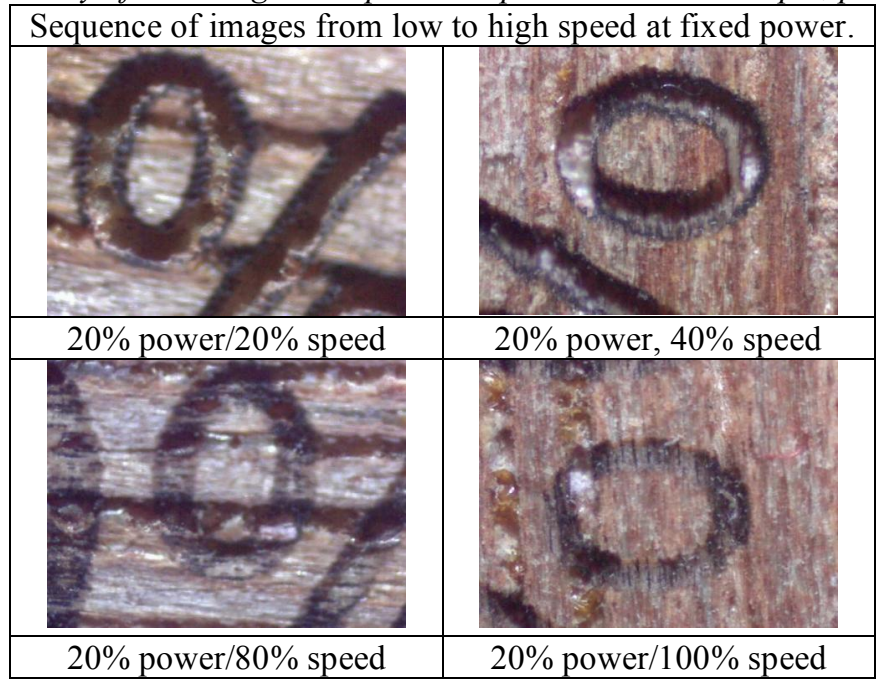


Figure 2. Student study of laser engraver resolution on acrylic. This portion of the test graphic was a solid rectangle, and the photographs are at $200 X$.



\section{Statewide Dissemination}

Not many of the Connecticut Community Colleges have the resources to implement the entire A.S. in Manufacturing and the Laser Manufacturing Option. However, through the College of Technology Technological Studies program, they are able to implement the key courses. Three Rivers is committed to assisting sister colleges by offering optics and laser courses by distance learning on the Internet or through hybrid online/onsite delivery.

\subsection{Introduction to Photonics Online}

Introduction to Photonics has been offered as an online laboratory course since 2001. Students perform experiments designed for a "home lab" environment, using commonly found supplies and the Optical Society of America's Optics Discovery Kit (available from Edmund Optics). The course was completely redesigned as a result of the NSF/ATE project PHOTON2, which incorporated adult learning principles and created a collaborative version of the course for online teacher professional development. Based on the PHOTON2 experience, the course is now less instructor-centric, and requests student collaboration on home labs. It is an ongoing challenge to convince technology students of the value of teamwork and collaboration.

\subsection{Introduction to Lasers Hybrid Course}

In Fall 2007, Introduction to Lasers will be offered as a hybrid online/onsite course. Current plans include the podcasting of Power Point based lectures, and some limited use of online computer controlled experiments. Oncampus classes will still be held for traditional day students, mainly to discuss and review the online podcasts, and most labs will be held on campus in the evening. Quite a few students who have expressed interest in taking the 
course are working for companies that build lasers, for example, Trumpf or IPG Photonics. Three Rivers is exploring the possibility of granting credit to such students for the laboratory portion of the course. There is ample precedent for credit for industry experience offered by technology programs at TRCC.

\section{Marketing- Where are the students?}

Despite the difficulties manufacturers are having in finding qualified employees, the perception that manufacturing has no future makes it difficult to recruit students to manufacturing programs. Along with the RCNGM, Three Rivers is embarking on a vigorous marketing program to encourage young people to explore careers in high tech manufacturing. Through a DVD produced by the RCNGM and available through online streaming video, newspaper articles, personal visits to high schools, radio interviews, and a three-day "Laser Camp" at the college, the message is, "There's a great future in Connecticut manufacturing-and it's not your grandfather's factory job any more!" Time will tell if the message is heard by prospective students and heeded.

\section{Acknowledgements}

Regional Center for Next Generation Manufacturing

Funded in part by the Advanced Technology Education Program of the National Science Foundation (ATE \# ATE 0402494) Principle

Investigator Karen Wosczyna Birch, Connecticut Community Colleges

Project PHOTON 2: Web-based Collaborative Learning, Teacher Enhancement and Laboratory Development Project

Funded in part by the Advanced Technology Education Program of the National Science Foundation (ATE \# ATE 0302528) Principle

Investigator (Project Manager) Fenna Hanes, New England Board of Higher Education

The authors thank Professor Patrick Knowles of Three Rivers Community College Manufacturing Engineering Technology

\section{References}

[1] http://www.cbia.com/newsroom/surveys/default.htm\#manufacturingjobs

[2] http://www.cord.org

[3] Massa, N. M., Masciadrelli, G. M. (1997). The Development of a Laser Machining Curriculum: An Interdisciplinary Approach. LIA Journal of Laser Applications, Orlando, FL

[4] The complete Laser Manufacturing Technician Competency Profile and Outline are available from RCNGM 